\title{
Identitat col-lectiva i imaginari popular en l'aplec de jocs tradicionals de Valls de mossèn Ribas
}

\author{
Albert Oliva Ramal \\ Universitat Rovira i Virgili \\ albert.oliva@urv.cat
}

RESUM

Aproximar-se al món del joc tradicional és descobrir el folklore, els costums, els usos, la llengua, la història, les creences, l'art i les llegendes d'un territori. Alhora, és difícil dissociar el joc tradicional del comportament humà, i l'estudi del joc folklòric de l'etnografia i l'etnologia. L'aplec de jocs tradicionals de Valls (I95I) d'Eusebi Ribas és un mirall precís de bona part dels elements i característiques dels seus participants, del dia a dia, de l'entorn que envolta aquesta identitat col-lectiva i de tot un imaginari comú, popular, dinàmic i social.

\section{PARAULES CLAU}

Eusebi Ribas; folklore; identitat; joc tradicional; Valls

\begin{abstract}
To study traditional games is to discover the folklore, customs, uses, language, history, beliefs, art and legends of a territory. At the same time, it is difficult to disassociate traditional games from human behaviour or to separate the study of folklore games from ethnography and ethnology. The "Aplec de jocs tradicionals de Valls" (Collection of traditional games of Valls) (I95I) by Eusebi Ribas is an accurate reflection of a large part of the elements and characteristics of those who played these games, of day to day life, of the atmosphere surrounding this collective identity and of a whole series of common, popular, dynamic and social phenomena.
\end{abstract}

KEYWORDS

Eusebi Ribas; folklore; identity; traditional games; Valls

REBUT: 2I/O3/2OI8 | ACCEPTAT: 22/O5/20I8 


\section{L'aplec de jocs tradicionals de Valls d'Eusebi Ribas Vallespinosa'}

Al llarg d'un territori, en un moment i lloc concrets, hi pot haver mostres de l'estudi i de la recol-lecció de materials folklòrics que testimonien el desenvolupament, el perfil i l'evolució d'aquestes formes a través del temps. L'estudi d'aquestes expressions permet valorar i fixar-les determinadament en una salvaguarda física, ja que moltes vegades el patrimoni immaterial passa desapercebut entre els usuaris. També, sovint, és massa obviat com a recurs accessible i popular que és.

En aquest àmbit, el prevere vallenc Eusebi Ribas Vallespinosa ${ }^{2}$ l'any I95I confecciona un aplec titulat «Folk-lore Vallenc. Jocs amb auca i llur descripció històric-etimològica», que pretén posar en relleu un valuós corpus inèdit de jocs tradicionals recollits a Valls (Alt Camp) en les darreries del segle xix i la primera meitat del xx. L'aplec, que recull cent sis jocs tradicionals vallencs, és un relligat de fitxes manuscrites amb fil, amb cobertes de cartró folrades de paper, amb títols i complements il-lustratius propis de mossèn Ribas i està estructurat en cinc apartats diferenciats: en el primer, titulat «Eleccions», el compilador anuncia en cada cas les normes dels jocs «per saber qui ha de governar i qui ha de parar»; el segon apartat, amb el títol «Finalitat», es presenta com a justificació del treball amb motiu dels Jocs Florals de la Mare de Déu de la Candela de I95I; amb l'«Entrada», Ribas introdueix la significació que té el món dels jocs infantils en la idiosincràsia social i personal de cadascú, i la concreta relació en el cultiu del cos i la ment que es dona en aquestes pràctiques; el quart apartat el forma la descripció dels jocs tradicionals recollits a Valls, i, finalment, el prevere afegeix un índex al final del manuscrit amb la numeració dels jocs recollits ordenats alfabèticament. L'obra, en conjunt, gaudeix d'una incipient personalitat, amb identitat i de contingut quantiós, i la disposició dels elements de cada punt és una realitat des del record del passat. De fet, aquesta és una de les identificacions més absolutes de la marca personal de l'autor, ja que si el joc ja no es mantenia prou viu, el clergue té bona cura de despertar-ne l'interès amb informacions relacionades amb la societat del moment que aconsegueix a partir d'altres àmbits temàtics com la cultura popular, el món de l'esport, el calendari festiu de la ciutat, els vallencs il-lustres...

Com s'ha dit, la sistematització que fa Ribas dels materials de l'aplec segueix un ordre alfabètic, i cada joc té una numeració recollida en un índex al final de l'obra amb el nom. L'autor hi dona el toc precís d'excel-lència amb una il·lustració a tall de gravat, escenificant una situació del joc que s'exposa en un espai concret de la ciutat, característic, reconegut i amable. En tots els casos, cada il·lustració va acompanyada d'un vers, un aforisme propi de l'autor que explicita la situació amb

\footnotetext{
I Aquesta comunicació s'emmarca en una línia d'investigació sobre literatura popular catalana que ha rebut finançament del Ministerio de Economía y Competitividad a través del projecte d'R+D: FFI20I5-64I28-P (MINECO/FEDER). Així mateix, forma part del treball realitzat pel Grup de Recerca Identitats en la Literatura Catalana (GRILC), reconegut i consolidat per la Generalitat de Catalunya (20I7 SGR 599).

2 Eusebi Ribas Vallespinosa (Valls I874-I959) va ser sacerdot, teòleg, escriptor, periodista, fotògraf i folklorista. Entre els anys vint, trenta i quaranta del segle xx inicia una tasca centrada en l'estudi del folklore i l'estrat popular de la societat. Es dedica a recol-lectar tot tipus de materials que fan referència a expressions folklòriques genuïnes del caràcter lúdic social, com són els jocs tradicionals, el ritual de les festes, les cançons populars, localitzades en els carrers i les cases d'un Valls encara rural, senzill i humil, que ell se sent proper i immediat per la seva condició de capellà.
} 
una advertència seqüencial, jugant amb la rima de la denominació i una paraula rellevant. Alhora, la descripció que se segueix és, en la majoria dels casos, similar. Una primera narració detallada de la seqüència de l'activitat dona pas a un breu apunt lingüístic, amb l'etimologia d'un mot que, per aproximació, intenta descriure el nom de cada joc. A més, en la majoria de jocs recollits, també es troba una contextualització de l'activitat amb el referent més immediat, el Valls que tothom coneix, a través de les anècdotes o els apunts històrics i folklòrics que acaben de complimentar-ne la descripció.

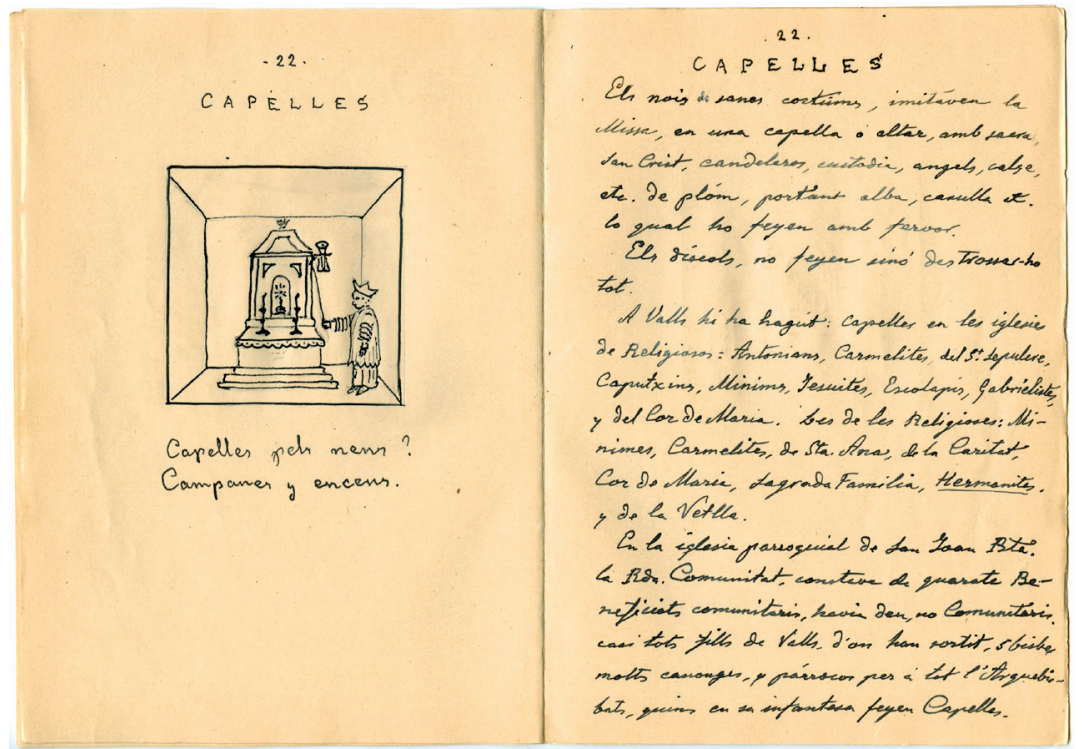

[Figura I] Exemple d'una fitxa manuscrita d'un joc, amb il·lustració, aforisme i descripció amb component folklòric.

Sovint, la història que existeix darrere de cada objecte n'enriqueix exponencialment el contingut. És el cas de bona part de l'obra d'Eusebi Ribas i, en concret, del recull manuscrit de jocs tradicionals esmentat. L'última etapa de la vida del prevere, entrada la dècada dels anys cinquanta del segle xx, va estar marcada per una situació personal i econòmica precàries. Ribas utilitza part de la seva obra com a moneda de canvi per tal de pagar productes de necessitat amb l'avinentesa d'alguns comerciants propers. En aquest context, l'aplec dels jocs vallencs va anar a parar a la farmàcia de Joan Vives Ferrater, situada a la cèntrica plaça del Blat de la ciutat. Recentment, els seus descendents han cedit el manuscrit a l'Arxiu Municipal de Valls i s'ha incorporat al fons personal del clergue, fet que ha permès posar-lo a l'abast dels estudiosos i de tota la ciutadania.

A través d'una panoràmica prou àmplia i afectiva, Eusebi Ribas, amb aquest aplec de jocs, té la pretensió de mostrar la riquesa de l'enginy dels nostres xiquets plasmat en aquestes formes lúdiques. En l'aplec, s'hi configura un perfil d'ésser humà social que és el dinamitzador i eix principal de l'acció, amb uns valors que canvien en funció del temps i del context cultural des del qual s'analitza. Aquests valors actuen a través de la identitat col-lectiva, i són compartits per tot un con- 
junt social i cultural. L'eix d'anàlisi d'aquest article parteix, doncs, de la concepció de la identitat col-lectiva i els seus valors com a identitat local immediata. Aquests elements ciutadans, folklòrics i culturals són plasmats en l'aplec de jocs tradicionals de Valls de formes diverses, ja que el concepte de valor simbòlic i d'identificació en la descripció dels jocs és el que contribueix, en major manera, a l'establiment de les identitats col-lectives que empren aquests béns com a referent comú.

\section{La identitat col-lectiva i local en l'aplec}

Els jocs tradicionals formen part del patrimoni immaterial de la societat, i són un llegat que pertany a tots els que s'hi identifiquen. Les persones, en aquest sentit, es guien per identitats col-lectives que reflecteixen una comunitat, uns valors i determinen unes preferències. Entre els diversos àmbits col-lectius, l'expressió del joc té un pes primordial i ocupa un espai quotidià ampli. Alhora, l'acció de jugar pren la identitat com a posicionament i símbol, i és font de cohesió social.

La gran vàlua d'aquestes formes lúdiques justifica la necessitat d'atendre els punts febles que existeixen en el coneixement i en la perpetuació d'aquestes expressions folklòriques. En el territori hi ha treballs que permeten establir un estat de la qüestió amb un plantejament i unes característiques similars al d'aquest article. Així, doncs, alguns dels treballs consultats, com a punt de partida al tractament que han fet altres autors sobre la temàtica que ens ocupa, són Jochs de la infancia (1874), de Francesc Maspons i Labrós; algunes anotacions sobre jocs infantils a Arxiu de Tradicions Populars (I928), revista dirigida per Valeri Serra i Boldú; Jocs tradicionals de brivalla i de joventut de Reus (I977), de Josep Iglésies; El jugar de l'Amades (I996), d'Imma Marin i Olga Prado; Els jocs tradicionals al Pallars Sobirà (2003), de Pere Lavega i Glòria Rovira; Jocs tradicionals d'Alcalà de Xivert (2010), de Joan Sanz i Vicenç Sancho, o altres monografies d'aplicació didàctica més concreta amb reculls de jocs infantils tradicionals com Un, dos, tres, pica paret! (2000), de Josep Maria Allué.

Primerament, per entendre el concepte de joc tradicional com a fet patrimonial d'un individu que constitueix, al mateix temps, una col-lectivitat, cal partir dels coneixements i emocions que suscita la matèria a través de la memòria compartida, que configura, tanmateix, la identitat col-lectiva. A més, aquesta identitat, present en l'esfera de l'imaginari popular, no només genera lligams sentimentals o emocionals, sinó que té una funció instrumental que n'explica la pervivència. En els diversos àmbits que configuren la societat, es poden localitzar diversos patrimonis vitals. El cas que ens ocupa, l'etapa infantesa, d'oci o de gatzara, resta repleta d'expressions i formes tangibles que potser no tenen un valor immediat però sí que donen identitat a un grup i el singularitzen: la família, l'entorn proper, l'àmbit geogràfic o la nació. El valor emotiu i simbòlic de l'activitat moltes vegades conviu, altament significat, amb la socialització i la configuració de les identitats col-lectives. En aquest sentit, els jocs tradicionals tenen uns grans atributs d'identitat collectiva que moltes vegades subratllen allò que és propi davant del que és aliè. Són un tipus de patrimoni cultural que narra i testimonia la manera de fer d'un sector social i construeix un entorn que dona sentit de pertinença a l'individu.

En segon lloc, els jocs són imaginatius en crear espais, joguets i objectes. També són interculturals i amb les dinàmiques dels jugadors d'una mateixa comunitat s'afavoreix la relació entre persones de la mateixa edat i d'una forma interge- 
neracional milloren la sociabilitat. Alguns jocs, fins i tot, poden tenir algun risc, cosa que afegeix més emoció i fa créixer. Tanmateix, la majoria d'accions prevalen sense cap càrrega instructiva, existeixen amb la finalitat de jugar per jugar i de passar-s'ho bé sense necessitat d'atendre, aparentment, a qüestions didàctiques i morals. És en aquest jugar per jugar que hi trobem el seu valor en fer persones felices i lliures, desfogades d'energia i preparades per anar a l'escola o a treballar (Oliva 20I7: 9).

Amb tot, l'enfocament que fa Eusebi Ribas del món del joc, el que es troba en els carrers d'un nucli poblat com Valls, posa en valor un seguit de relacions amb el medi immediat: l'oci, les feines, la religió, els fenòmens naturals, les festes, els animals, la família... Per al clergue, la quotidianitat usual del joc és una creació humana que se suporta, des de l'antiguitat, de la interacció entre homes i dones, xiquets i imaginari, i es basteix de projeccions culturals i vincles emocionals. La cultura esdevé l'eina bàsica de socialització i de transmissió dels valors que compartim com a poble, i el jugar més espontani es converteix, inevitablement, en una mostra de la vitalitat de la població. La creació d'aquestes imatges vitals ens pot mostrar el que hem estat, el que som o el que ens agradaria ésser. Són icones del tot tangibles, evidenciades de moltes maneres, i alimentades per un món mental i un temps col-lectiu. El joc tradicional, alhora, forma part d'algunes etapes de vida i contribueix a crear-ne; també enriqueix i reprodueix el curs d'una societat i, més immediatament, el d'una població.

En aquest sentit, Bienve Moya, en el llibre Cada dia és festa, apunta que l'espai del joc també reclama una diversitat de sectors, d'estrats i de generacions. Cada capa, cada grup que juga, pot tenir un paper concret en l'acció o protagonitzar-ne una part, a condició que cadascuna d'aquestes parts es reconegui com un tot social. El jugar es desenvolupa, en bona manera, en l'espai públic i comú, i s'acull en sectors amb tota mena d'afinitats col-lectives: socials, d'edat, sectorials... Ara bé, és en l'espai públic on el joc popular pren la dimensió social (Moya 2OI4: Io). Tanmateix, segons Ribas, que un joc s'implanti i es desenvolupi en un indret concret és símptoma que alguna herència condueix els infants a preferir uns espais i, fins i tot, a menystenir-ne uns altres. A continuació, amb l'anàlisi d'una desena de jocs de l'aplec, es posa de manifest la pretensió de l'autor de mostrar un patrimoni intangible, amb molts elements subjacents i imperants, que han convertit aquesta obra manuscrita en un text que va molt més enllà d'un mer inventari de jocs localitzats en uns espais concrets. A més, l'anàlisi de tots aquests elements descriptius de socialització i d'arrelament en la comunitat posa de manifest els diversos àmbits i sectors de la identitat col-lectiva i l'imaginari popular del Valls d'una època i d'una societat.

\subsection{Jocs de corda i d'espardenyeta}

Per arribar a copsar la veritable connexió que fa Eusebi Ribas entre les expressions populars en forma de joc tradicional i la configuració d'unes identitats culturals i socials, es poden destacar, per exemple, els jocs de corda i d'espardenyeta. La dinàmica del primer joc consisteix a saltar, amb cant o al mut, amb una corda sostinguda per dos jugadors en els extrems, mentre que en el segon joc l'interès consisteix a fer una rodona de nois asseguts a terra i passar una espardenya, ocultament, per sota del pont de les cames, amb la finalitat que el qui para no pugui 
interceptar l'objecte. Així, les dues activitats tenen per element principal de l'acció el cànem, material amb el qual es fan les cordes i les espardenyes. Ribas aprofita l'avinentesa per relacionar aquests elements amb l'antiga organització dels oficis a la ciutat per gremis i confraries, encara vigent a l'època, i la corresponent vessant folklòrica que se'n deriva amb les manifestacions al carrer amb motiu de les seves festes patronals.

El gremi de corders vallenc era nombrós, i al llarg dels carrers es repartien filadors que adobaven el fil o la corda amb torn. Aquest gremi, amb la consegüent confraria juntament amb el gremi d'espardenyers, estava sota l'advocació de sant Pau. L'interessant d'això és l'apunt folklòric que fa Ribas entorn de la festa patronal d'aquests gremis. Deia: «Per a la festa sortia una comparsa al més típic gust folklòric i, de castells, s'hi feien els millors» (Ribas I95I: 45). En aquest sentit, per anunciar la festa de la conversió de sant Pau, a la vigília sortia una cavalcada amb tres cavalleries i llurs heralds. Muntava un timbaler amb casaca i barret apuntat amb timbales, un xiquet vestit d'àngel amb una campaneta que anunciava completes i predicador, i el personatge de sant Pau amb careta, barba i una colossal espasa. Aquesta escenificació popular es va mantenir durant bona part del segle XVIII i XIX, i es té notícia que va sortir al carrer per últim cop l'any I9Io després d'anys de no fer-ho, amb afany de recuperar aquest bell costum. Ben aviat, però, l'escenificació va tornar a caure en l'oblit.

Alhora, d'entre el nombrós patrimoni de la confraria de sant Pau, el gremi custodiava la figura festiva de la Mulassa, que sortia a ballar, al carrer, en les diades més assenyalades de la ciutat en seguici processional. En aquest sentit, els dos jocs tradicionals esmentats, que combinen elements motrius com l'habilitat, la lleugeresa, l'equilibri i la propulsió, sovint acompanyen les activitats de destresa física amb versos i cantarelles. Així, doncs, una de les moltes aportacions folklòriques que fa mossèn Ribas en la descripció d'aquests dos jocs és en forma de cantarella popular, ${ }^{3}$ que s'empra com a element dinamitzador de l'activitat i, alhora, narra d'una manera breu i subordinada les característiques i la idiosincràsia d'aquesta figura festiva: ${ }^{4}$

La Mulassa, santa plaça, la Mulassa dels corders, vinguin metges i barbers, per curar la Mulassa.

3 Malauradament, Eusebi Ribas no recull la notació musical dels materials folklòrics, a causa, potser, de la manca de formació o la desconeixença en aquest àmbit.

4 Ja en el segle XVIII hi ha documentada la figura festiva de la Mulassa, que formava part del ric i extens seguici cerimonial de Valls. Segons la veu popular, en un moment inconcret es va calar foc a aquest element i se'n va perdre la tradició. L'any I987, la figura festiva es va reintroduir al si de les festes vallenques. 


\subsection{Jocs de capelles i de mia múndia}

Moltes vegades, quan els xiquets no es troben amb un joc de mecànica establerta, es lliuren espontàniament a la inventiva per imitar o calcar fets de la vida que han vist esdevenir-se al seu voltant, és a dir, simulen fer allò que fan els grans. Així, molts jocs d'imitació reprodueixen escenes familiars i es calquen referents culturals i festius propers, ja que els jugadors imiten les activitats. En el cas dels jocs de capelles i de mia múndia, la religiositat popular resulta imperant a peu de carrer, amb unes formes lúdiques que tracten el tema d'una manera espontània, senzilla i alliberada, això sí, de la càrrega espiritual que comporten les pràctiques litúrgiques habituals.

En aquest sentit, un dels àmbits més presents en la descripció dels jocs i que fa singular el recull de Valls és l'element religiós. Cal suposar que mossèn Ribas l'introdueix per la condició que té com a clergue i recol-lector dels materials. Es troben referenciats dominis de la cultura religiosa de la ciutat en diversos jocs, també presents com a imitació. Els jocs de capelles o de mia múndia basen l'acció a reproduir els elements sacres més immediats de la societat del moment, com l'ofici d'ermità i l'acció de dir missa o beneir. En el primer cas, els xiquets imiten l'ofici de dir missa i reprodueixen, físicament, una capella o altar amb tota mena d'objectes replicats com imatges sacres, candelers, estovalles, calzes... En el segon joc, la dinàmica consisteix a fer una capelleta de paper, amb unes portelles que es tanquen i, si es vol veure l'estampa o el sant que guarda l'interior, s'ha de fer una petició mitjançant una cantarella i donar alguna cosa per tal que s'obrin les portes.

No obstant això, no s'ha d'agafar estretament el significat d'aquests elements religiosos en el sentit de devot o beat, ja que això tan sols aporta, en bona part, el testimoni d'un vestigi, una manera de fer i la inèrcia social imitada. Realment, aquestes mostres sacres espontànies són intents d'expandir la cultura religiosa social més enllà dels indicats estadis rigorosos, i els jocs autènticament populars o tradicionals es poden situar en un ambient més pagà o laic, amb elements dinamitzadors que desfiguren la connotació espiritual del seu origen.

\subsection{Jocs de castells i de toros}

En aquesta línia d'imitació cultural i d'identificació amb un indret, també es pot parlar dels jocs de castells o de toros, que són una recreació de manifestacions folklòriques localitzades en un espai geogràfic proper i un moment històric concret. En el primer cas, l'acció es basa en una simulació, a baix nivell, de les construccions humanes més memorables protagonitzades pels Xiquets de Valls que es poden veure a la plaça en les festes patronals de Sant Joan o Santa Úrsula i en els esdeveniments socials més destacats de la ciutat. Aquestes expressions també són molt freqüents arreu del Camp de Tarragona, el Garraf, l'Anoia i el Penedès, i esdevenen un referent cultural i festiu en el calendari tradicional d'aquestes zones geogràfiques. El joc inclou, també, imitacions personificades dels caps de colla vallencs de l'època, com Rabassó o Escolà, que evidencien l'emmirallament dels infants cap a unes figures modèliques i mediàtiques reconegudes socialment.

En el segon cas, la reproducció d'una corrida de braus és molt més simple i casolana, ja que l'acció es basa a posar els punys damunt del cap i envestir els jugadors que fan de pretendents de torero. En aquest cas, s'empara en un referent cul- 
tural que no és genuí, però que pot ésser familiar a causa de les actuacions populars de toreros de renom a les places de braus de Tarragona o Barcelona. Les corrides de braus que es fan a Tarragona, a l'època, són una de les principals atraccions lúdiques per als vallencs i vallenques a finals del segle xix. De fet, ambdós jocs són una mostra del pes que tenen els referents culturals immediats, ja que a través de la imitació els xiquets emulen una manera de fer i plasmen les activitats en allò més excèntric i pintoresc de la població.

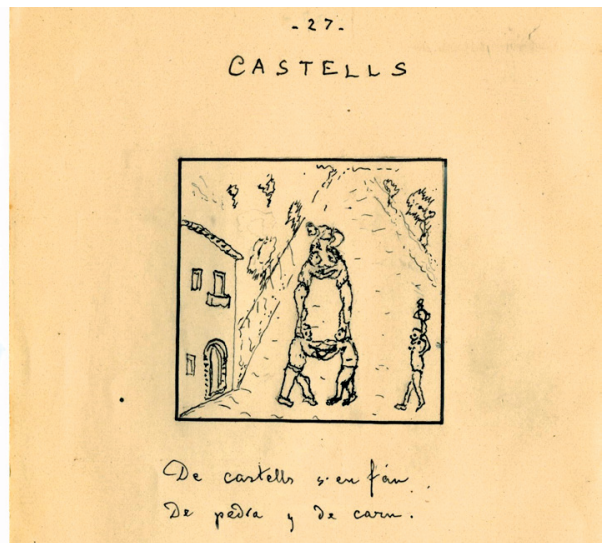

[Figura 2] Il·lustració del joc de castells.

\subsection{Joc de Jan Petit}

Un altre dels jocs interessants que ens evoca a tot un referent cultural i d'identitat és el de Jan Petit. En aquest cas, la centralitat de l'activitat recau en un jugador situat al centre de la rotllana que dirigeix els moviments dels jugadors que l'envolten amb una simple coreografia que reforça la cantarella. Hom pot pensar que és un joc molt freqüent arreu del territori, amb una dinàmica genèrica i usual. El que és interessant, però, és la contextualització que fa Eusebi Ribas del joc i de les pràctiques de gatzara que es produïen en aquell context a la ciutat vallenca a la meitat del segle xix. Així, doncs, en temps de carnaval diverses manifestacions de l'estil amenitzaven les estones de disbauxa i gatzara al carrer, impulsades a Valls per un tal Barrusques, un personatge pintoresc i singular al si de la societat vallenca més popular de l'època. De fet, segons el clergue, la figura de Barrusques va ser la creadora del ball popular de la Primera, ${ }^{5}$ que integra actualment els seguicis processionals de les diades més assenyalades, dansa feta ex professo en honor de la Mare de Déu de la Candela.

\footnotetext{
5 La primera referència documental d'aquest ball és per les Festes Decennals de la Mare de Déu de la Candela de i88I. Esdevé l'única dansa exclusiva de la ciutat malgrat que també hi ha notícies antigues de l'existència d'un ball de la Primera a Bràfim. En les cercaviles hi participen I2 balladors i és acompanyat per les gralles i el timbal. És una dansa destinada als xiquets. Forma part de les sortides rituals del seguici cerimonial de la ciutat en les completes, l'anada i la sortida d'ofici i el tomb del poble. També participa en els actes rituals de les Festes Decennals de la Mare de Déu de la Candela, cada Io anys. Tanmateix, al llarg de l'any, aquest ball vallenc pot realitzar diverses sortides arreu del territori, en festes patronals que es distingeixen per la significació, el caràcter tradicional i la qualitat.
} 


\subsection{Joc de lledons}

El joc de lledons és una altra pràctica de gatzara inclosa en l'aplec de jocs tradicionals de Valls que convé comentar. El joc consisteix a usar uns plomalls de canya com a canons, o ballestes amb goma, per llençar lledons, el fruit del lledoner, per fer salves, molestar o encertar un objectiu. En un primer moment, el joc pot esdevenir, tan sols, una pràctica de disbauxa amb el llançament a propulsió del fruit del lledoner, un recurs immediat i del tot econòmic per assolir un objectiu concret. Per exemple, les notes de Ribas esdevenen una veritable descripció del quadre folklòric de la festa de Sant Llorenç que Valls ha festejat des de temps immemorials. L'ermita vallenca que resta sota l'advocació d'aquest sant, avui malauradament sense culte, era capitanejada per un colossal lledoner més que centenari que testimoniava un aplec popular amb oficis, cant de goigs, àpats, balls de coques i danses populars. El clergue utilitza, doncs, l'element principal de l'acció, els lledons, per recuperar de l'oblit i deixar per escrit un seguit de pràctiques folklòriques que tenen poc a veure amb el món del joc tradicional, però sí que comparteixen tot un imaginari comú, popular, dinàmic i social que esdevé un autèntic element d'identitat de la ciutat.

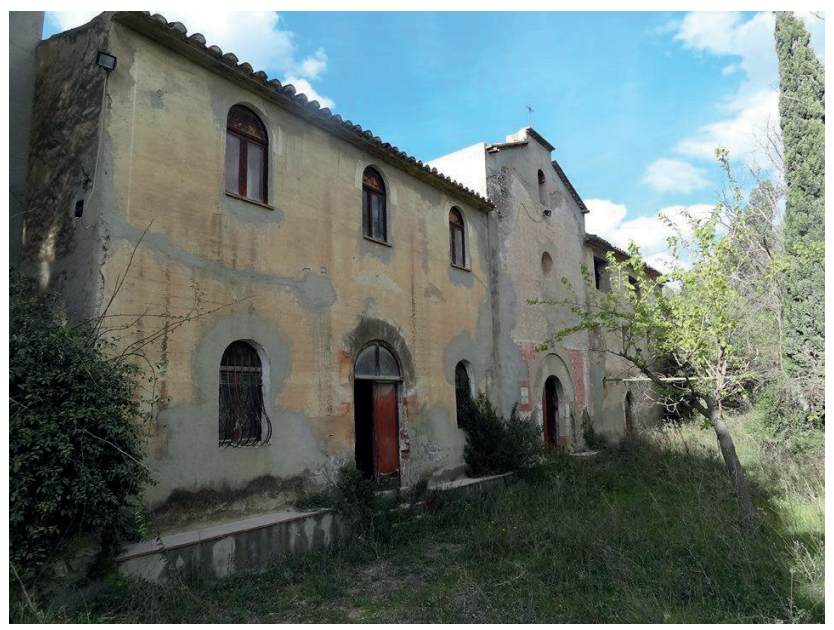

[Figura 3] Estat actual de l'ermita de Sant Llorenç del Bosc de Valls, amb el lledoner colossal desaparegut.

\subsection{Joc de pilota}

En un altre sentit, Ribas, en el joc de pilota, destaca un dels indrets més populars de la població, l'espai conegut popularment com a Joc de la Pilota, on els xiquets de moltes generacions van trobar la tangibilitat idònia amb unes condicions socials propícies per passar anys fent botar la bola sense una mecànica i normativa necessàriament establertes. El cert és que la fidelitat mantinguda a uns mateixos jocs i llocs, i la permanència a través dels anys en les activitats infantils, parlen per elles mateixes. Aquest fet ens serveix com a pretext per parlar de la denominació de Joc de la Pilota a un espai concret del municipi on es localitzaven aquestes activitats. De fet, aquest és un topònim que encara avui es manté vigent en moltes 
poblacions de Catalunya i, en el cas de Valls, el trobem referenciat en el lloc que comprenia la paret de l'antiga muralla medieval i el portal d'un dels ravals de la població. Ara, amb una forta càrrega simbòlica tangible en l'imaginari, cal destacar que físicament aquest espai ja no existeix a causa de la urbanització moderna que va patir la ciutat a finals del segle XIX, amb la muralla i el portal desapareguts, i que tampoc es fa botar la pilota amb la freqüència que hom desitjaria. Ara els espais d'esbarjo són uns altres. Tot i així, la gent de més edat de la ciutat encara es refereix a aquesta localització (actualment, carrer de Jaume Huguet) com a Joc de la Pilota, una denominació força estesa, també, a altres poblacions del país.

\subsection{Joc de ratapatxets}

Finalment, el joc de ratapatxets es podria definir com una de les activitats més cruels i escabroses que Ribas recull en el seu aplec, ja que la intenció principal del joc és la de finar l'animal a través d'una incandescent tortura. Els xiquets, mitjançant canyes o pals llargs, sortien al carrer durant el capvespre per caçar ratpenats o, com es diu a Valls, ratapatxets. Després de capturar-los, encara vius, els agafaven per les ales i les hi clavaven a una paret, on començaven a martiritzar-los. Amb una candela encesa els cremaven la cara i, llavors, la pobra bèstia obria la boca amb xiscles, que els nois deien que eren renecs i improperis. L'activitat acabava quan l'animal moria, clavat en creu, com Nostre Senyor.

La finalitat d'aquesta acció tan cruenta no és cap altra que la d'equiparar la crucifixió de Jesús, un personatge bo, amb la representativitat negativa d'aquesta bèstia. Per mitjà de l'acció, s'imparteix una «justícia social» que pretén alliçonar un ésser que s'associa a allò més maligne per antonomàsia, amb la convicció popular que la bèstia capturada és la viva representació del dimoni, omnipresent en els diversos estrats d'una societat amb una moral profundament cristiana. I és que un animal com el ratapatxet és concebut, per la cultura europea des dels primers temps, com un ésser al servei de Satanàs i, fins i tot, pot ser una ànima pecadora condemnada a volar pel món sense rumb ni empara.

\section{Conclusions}

A tall de conclusió, es pot afirmar que, a partir de l'anàlisi d'alguns jocs de l'aplec d'Eusebi Ribas, s'evidencia la pretensió de l'autor de mostrar alguna cosa més que un inventari d'expressions folklòriques o un llistat de jocs tradicionals de Valls. En primer lloc, es pot dir que en cada descripció dels jocs hi ha elements que sobrepassen la mera formalitat de l'acció i esdevenen una autèntica font d'informació d'altres elements folklòrics imperants en les manifestacions socials i culturals de Valls i el seu entorn. La societat, l'element dinamitzador del joc, no és mai immobilista i sempre evoluciona en funció de les circumstàncies socials, geogràfiques, demogràfiques i culturals. En aquest sentit, el protagonista actiu del joc pot alterar, retallar i afegir tot el que toca, i mesclar noves harmonies en el seu trenat folklòric. Alhora, en la vitalitat que encara ara poden mostrar alguns jocs de l'aplec de Ribas, es pot afirmar que no s'han gastat amb l'ús, sinó que han millorat en matèria i s'han enriquit i multiplicat. Això és propiciat per les variants que pot presentar un mateix joc arreu del territori, amb un procedir similar de moltes peces que interactuen simultàniament en un joc i un altre. 
En segon lloc, Eusebi Ribas també apunta que una manifestació en forma de joc popular entre els homes és una provatura, un tempteig, i per aquesta raó, entre d'altres, el joc usa el divertiment, ja que allò que es fa jugant dins d'aquest terreny no ha de portar conseqüències severes. El clergue concep el joc tradicional com un dels pilars bàsics de la cultura, un element dinamitzador de l'imaginari de l'espai comú i social, ja que aquestes formes populars han passat pel sedàs de les generacions que ens han precedit i tenen impregnats els costums i les tradicions més vigents d'una societat. El valor dels jocs consisteix en el fet que no són dirigits, és a dir, són lliures, i ocupen i dominen l'espai de la ciutat, els carrers, les places i els camins, tal com s'evidencia en les nombroses referències localitzades que aporta l'autor en l'aplec.

En tercer lloc, la connexió de l'àmbit cultural local en el món del joc tradicional recollit per Ribas també té per objectiu la configuració d'identitats. Entren en funcionament qüestions com la propietat simbòlica, l'apropiació emotiva i cognitiva, l'experimentació de situacions emprant el patrimoni com a escenari o la construcció de creacions artístiques, estratègies i accions basades, inspirades i destinades a fer que aquests elements patrimonials formin part de la memòria col-lectiva o individual.

En definitiva, segons Eusebi Ribas els jocs tradicionals són un mirall de bona part dels elements i característiques dels seus participants, del seu dia a dia i de l'entorn que els envolta. Cada poble té les seves tradicions i costums, i els seus jocs sovint plasmen el tarannà cultural i els distingeixen d'altres poblacions. Per tant, amb l'estudi del contingut d'un aplec de jocs tradicionals com aquest s'assegura que gràcies al saber dels mateixos jocs s'està coneixent i analitzant, a la vegada, la cultura més propera, la de més identitat i la més particular. D’aquesta manera, els jocs tradicionals formen part del nostre patrimoni cultural i tenim l'oportunitat de ser conscients d'aquests elements imperants en les formes lúdiques, al mateix temps que l'arreplega de tants i tants jocs són un mirall translúcid de la cultura comuna i compartida entre els seus participants. 
Albert Oliva Ramal

\section{Referències bibliogràfiques}

Allué, Josep Maria (200o): Un, dos, tres, pica paret! Jocs Populars i tradicionals. Barcelona: Editorial La Galera.

IGLÉSIES, Josep (I977): Jocs tradicionals de brivalla i de joventut de Reus. Reus: Edicions Rosa de Reus.

LAvegA, Pere; Glòria Rovira (2003): Els jocs tradicionals al Pallars Sobirà. Lleida: Garsineu Edicions.

MARIN, Imma; Olga Prado (I996): El jugar de l'Amades. Moixaines, cançons de sorteig i jocs, volum I. Tarragona: Edicions El Mèdol.

MASPONS I LABRós, Francesc (I874): Jochs de la infancia. Barcelona: Editorial Barcino.

MoyA, Bienve (20I4): Cada dia és festa. Barcelona: Editorial Barcino.

OLIVA, Albert (20I7): El carrer popular. Jocs de tradició a Valls. Valls: Edicions Quart Minvant.

RIBAS, Eusebi (I95I): «Folk-lore vallenc. Jocs amb auca i llur descripció històrico-etimològica». (Manuscrit inèdit.)

SANZ, Joan; Vicenç SANCHO (20IO): Jocs tradicionals d'Alcalà de Xivert. Sant Carles de la Ràpita: Col-lecció Temes Gaspatxers.

SERra i Boldú, Valeri (dir.) (I928-I925): Arxiu de Tradicions Populars, 7 fascicles. Barcelona. 